\title{
Clinical, physiological, and psychological study of asthmatic children attending a hospital clinic
}

\author{
MARY NORRISH, MARIAN TOOLEY, AND SIMON GODFREY \\ From the Department of Paediatrics and Neonatal Medicine, and Department of Psychological Medicine, \\ Hammersmith Hospital, London
}

SUMMARY The results of an investigation into the relationship between clinical, physiological, and psychological factors in 63 children with asthma are reported. The children were classified according to the severity of their asthma by reference to their regular drug usage and also were assessed in terms of the quality of control of the asthma and the degree of compliance with medication. Lung function tests and exercise tests were also carried out. Standard questionnaires to detect emotional or behavioural 'deviance' in the children were completed by their mothers and by class teachers and assessments made of their personalities and the mental health of their mothers. Though the percentage of children with deviant scores on the questionnaire was high, it was not much greater than had been found among other (nonasthmatic) London children.

Resting peak flow rate, measured as the mean of at least three tests on different clinical attendances, reflected the clinical grading of severity. Deviant children had lower levels of peak flow than nondeviant children, but their bronchial lability as measured by exercise-induced asthma was similar. Poor control of the asthma was associated with emotional or behavioural deviance, whereas deviance was independent of the severity of the asthma per se.

The role of psychological factors in the aetiology of childhood asthma and in the precipitation or aggravation of asthmatic attacks has been the subject of many investigations. Psychological factors studied have included the child's personality, emotional disturbance in the child, parental attitudes, and mother-child interaction (Alexander, 1950; Rees, 1956; Pinkerton, 1967), but there are few well-established findings.

Two recent epidemiological studies (Graham et al., 1967; McNichol et al., 1973) indicated that emotional or behavioural 'deviance' was not significantly more common among the whole range of asthmatic children than among children in the general population. Only the group of children most severely handicapped by asthma included a higher proportion of deviant children.

The first study (Graham et al., 1967) did not include detailed clinical assessment, and classification of the children into mild or severe cases was made on the basis of information from parents and teachers about the amount of schooling missed and the extent to which asthma interfered with activities

Received 2 May 1977 such as sports and games. In the second study (McNichol et al., 1973), while all the children had suffered from asthma at some time during their lives, approximately $50 \%$ had been symptom free for 12 months or more and the results of earlier assessments made when the children still had symptoms were not reported. Our study was undertaken in an attempt to clarify the relationship between emotional or behavioural deviance and the severity of the child's asthma.

\section{Method}

Selection of patients. The sample was made up of children aged between 8 and 15 years on 31 July 1975 , all of whom had been attending the Asthma Clinic at Hammersmith Hospital long enough to be stabilized on their drugs (at least 6 months). The parents of all children who fulfilled the selection criteria were approached, and 64 out of a total of 69 agreed to take part. One child was subsequently dropped from the study because insufficient information was obtained from his parents. There were 40 boys and 23 girls in the sample, with a mean age of 10 years 5 months. Nearly half the children were 
under 10 years of age. The majority of the children $(75 \%)$ came from Hammersmith or other West London Boroughs, $12 \%$ came from other parts of London, and $12 \%$ came from outside London. $27 \%$ of the children were of West Indian or Asian parentage. The sample was thus representative of asthmatic children in the upper age group attending a hospital clinic in London, and included a substantial immigrant minority.

\section{Assessment procedures.}

Clinical measures. The severity of each child's asthma was classified according to the type of medication regularly prescribed over the past 6 months as the best overall index of severity. The children were all supervised in a clinic where decisions to move from simple bronchodilator therapy to sodium cromoglycate and then to steroids were based on objective data collected with the help of diaries and peak flow recording at home (Godfrey, 1974). All of the children fell into one of these drug groups, which were termed mild, moderate, and severe.

In addition, each child was rated on a 5-point scale to indicate adequacy of control by medication and adequacy of drug administration. These judgements were based on information from the case notes of the previous 6 months. Also noted were the comments of the physician who saw the child, the simple spirometric measurements made in the clinic, and the diary records of symptoms and home peak flow measurements when available. This assessment was made by the physician without knowledge of the results obtained by the psychologist.

Physiological measures. Peak expiratory flow rate (PEFR) was measured whenever the children visited the clinic, and was expressed as a percentage of the expected peak flow rate for children of the same height (Godfrey et al., 1970). A physiological measure of the condition of most of the children was provided by calculating the mean per cent of expected peak flow rate where the child had visited the clinic on three or more occasions from July 1974 to July 1975. In addition, each child performed a treadmill exercise test as described by Connolly and Godfrey (1970) to measure bronchial lability.

\section{Psychological measures.}

(a) The Rutter ' $A$ ' scale (Rutter et al., 1970): a questionnaire for parents, containing 31 statements about the child's health and behaviour over the past 12 months. The parent indicates whether or not each statement applies to the child and if so, to what extent. Each item is scored 0 if it does not apply, 2 if it certainly applies, and 1 for the intermediate category. A score of 13 or more is taken to indicate 'deviance', and subscores are used to differentiate between 'emotional', 'conduct', and 'mixed' disorders. ' $A$ ' scale scores were obtained for all 63 children and the questionnaire was completed by the child's mother in all but one case.

(b) The Rutter ' $B$ ' scale (Rutter et al., 1970): a questionnaire for teachers consisting of 26 statements, 23 of which are identical to statements on the 'A' scale. Items are scored 0,1 , or 2 , as above. A score of 9 or more indicates an 'emotional', 'conduct', or 'mixed' disorder. 'B' scale questionnaires were completed by the class teachers and scores obtained for 61 children.

(c) The Malaise Inventory (Rutter et al., 1970): a health questionnaire for mothers which concerns her own mental state. It was included to explore the relationship between the child's clinical status and the mother's mental well-being. The inventory was developed for use in Rutter's epidemiological study in the Isle of Wight (Rutter et al., 1970) and consists of 24 items referring to the emotions or aspects of the physical state which have an important psychological component.

(d) The Junior Personality Questionnaire (Eysenck and Eysenck, 1975): children's version of the Eysenck Personality Questionnaire. It was included to investigate the relationship between the child's personality and the severity of the asthma. The most important scores to be derived from this questionnaire measure emotionality and extraversion.

\section{Results}

Rutter Parental Questionnaire ('A' scale) and Teachers' Questionnaire ('B' scale). 28 of the 63 children $(44 \%)$ were identified as 'deviant' by the parental questionnaire (18 boys, 10 girls), and 11 of these children were also selected by the teachers' questionnaire. Teachers' questionnaires were returned for 61 children and of these, $17(28 \%)$ had deviant scores (10 boys, 7 girls). There was no significant difference between the proportion of boys and the proportion of girls selected by either scale.

The children with deviant scores on either of the Rutter scales were classified as having an emotional, conduct, or mixed disorder, and the number of children in each group is shown in Table 1. Mothers were more likely to place their children in the emotional group than the conduct disorder group. However, among the children selected as deviant by the teachers' questionnaire, subscores indicated just 
Table 1 Rutter scales: classification by nature of disorder

\begin{tabular}{lrlll}
\hline & 'Emotional' & 'Conduct' & 'Mixed' & Total \\
\hline 'A' scale & 19 & 5 & 4 & 28 \\
'B' scale & 7 & 7 & 3 & 17 \\
\hline
\end{tabular}

as many conduct disorders as emotional disorders. There was low agreement between mother and teachers about the classification of the 11 children selected by both scales with only 4 placed in the same category.

The Malaise Inventory. Scores on the Malaise Inventory ranged from 0 to 15 with a median score of 4.64. Mothers of children with deviant scores on either or both the Rutter scales were more likely to score above the median than were mothers of nondeviant children $\left(\chi^{2}=4 \cdot 07, \mathrm{df}=1, \mathrm{P}<0 \cdot 05\right)$.

Junior Personality Questionnaire. Scores from the personality questionnaire were converted to standard scores with a mean of 0 and a standard deviation of 1 , thus making it possible to rank all the children on two orthogonal dimensions: emotional-stable and extravert-introvert. Children scoring within $1 \mathrm{SD}$ of the mean in either direction were considered to fall within the normal range. Those with scores more than $1 \mathrm{SD}$ above the mean were termed 'high scorers', and those with scores more than 1 SD below the mean were termed 'low scorers'. Table 2

Table 2 Scores on the Junior Personality Questionnaire

\begin{tabular}{llll}
\hline & 'Low' & 'Normal' & 'High' \\
\hline Emotionality & 10 & 43 & 10 \\
Extraversion & 20 & 41 & 2 \\
\hline
\end{tabular}

shows that emotionality scores were normally distributed. On the extravert-introvert dimension the majority of children had 'normal' scores. However, the distribution was skewed to the left and there were 20 low scorers (introverts) and only 2 high scorers (extraverts). The scores suggested that the Hammersmith children were not more emotional than children in the general population, but that there was a preponderance of introverted children in the sample. None of the 10 children with high scores on the emotionality dimension fell into the introvert or extravert groups and there was no association between deviant scores on the Rutter scales and 'abnormal scores' on the personality questionnaire.
Intergroup comparisons.

Severity groups. There were 17 children with mild intermittent asthma, treated with bronchodilators; 23 children with continuous, moderately severe asthma treated with sodium cromoglycate; and 23 children with severe asthma who took steroids continuously. Comparisons between these groups on scores from psychological measures were as follows.

(a) Rutter scales. The distribution of deviant children among the 3 severity groups is given in Table 3 and while the mild asthmatics had the largest

Table 3 Distribution of deviant children among severity groups

\begin{tabular}{llll}
\hline & Severity & & \\
\cline { 2 - 4 } & $\begin{array}{l}\text { Mild } \\
(n=17)\end{array}$ & $\begin{array}{l}\text { Moderate } \\
(n=23)\end{array}$ & $\begin{array}{l}\text { Severe } \\
(n=23)\end{array}$ \\
\hline Deviant & $11(65 \%)$ & $10(43 \%)$ & $13(57 \%)$ \\
Nondeviant & $6(35 \%)$ & $13(57 \%)$ & $10(43 \%)$ \\
\hline
\end{tabular}

proportion of deviant children $(65 \%)$, there was no significant association between deviance and the severity of the asthma.

(b) Malaise Inventory. The mothers were divided into those scoring above and below the median score of $4 \cdot 64.59 \%$ of the mothers of mild asthmatics scored above the median, compared with $52 \%$ and $43 \%$ in the moderate and severe groups respectively. There was no significant relationship between the severity of the child's asthma and the mother's mental well-being.

(c) Junior Personality Questionnaire. The two aspects of personality (emotionality and extraversion) were considered separately and comparisons made between children scoring above and below the median on each dimension. $61 \%$ of the children with moderately severe asthma scored above the median for emotionality compared with $47 \%$ and $52 \%$ in the mild and severe groups. There was thus no relationship between emotionality and the severity of the asthma. On the extravert-introvert dimension there was a clear but nonsignificant relationship between severity and introversion with the proportion of 'introverted' children increasing with the severity of the asthma (Table 4).

Quality of control groups. The quality of control of the asthma by medication was rated very good, good, average, and poor, and the distribution of mild, moderate, and severe asthmatics among the four 'quality of control' groups is given in Table 5. 
Table 4 Scores on the Junior Personality Questionnaire (extraversion)

\begin{tabular}{|c|c|c|c|}
\hline & \multicolumn{3}{|c|}{ Severity } \\
\hline & Mild & Moderate & Severe \\
\hline $\begin{array}{l}\% \text { extravert } \\
\% \text { introvert }\end{array}$ & $\begin{array}{l}70 \\
30\end{array}$ & $\begin{array}{l}57 \\
43\end{array}$ & $\begin{array}{l}39 \\
61\end{array}$ \\
\hline
\end{tabular}

Table 5 Severity and quality of control

\begin{tabular}{lccccc}
\hline Severity & \multicolumn{5}{l}{ Quality of control } \\
\cline { 2 - 6 } & Verv good & Good & Average & Poor & Total \\
\hline Mild & 13 & 3 & 0 & 1 & 17 \\
Moderate & 6 & 10 & 2 & 5 & 23 \\
Severe & 6 & 3 & 9 & 5 & 23 \\
Total & 25 & 16 & 11 & 11 & 63 \\
\hline
\end{tabular}

The number of cases in each cell was too small to allow for statistical analysis, but it was clear that 'severity' and 'quality of control', though related, were not synonymous. Comparisons between scores on psychological measures for the four quality of control groups therefore seemed justified.

(a) Rutter ' $A$ ' and ' $B$ ' scales. The percentage of 'deviant' children in each group is given in Table 6.

Table 6 Deviance and quality of control

\begin{tabular}{lllll}
\hline \multicolumn{4}{c}{ Quality of control } & \\
\cline { 2 - 5 } & $\begin{array}{l}\text { Very good } \\
(n=25)\end{array}$ & $\begin{array}{l}\text { Good } \\
(n=16)\end{array}$ & $\begin{array}{l}\text { Average } \\
(n=11)\end{array}$ & $\begin{array}{l}\text { Poor } \\
(n=11)\end{array}$ \\
\hline Deviant & $10(40 \%)$ & $9(56 \%)$ & $5(45 \%)$ & $10(91 \%)$ \\
Nondeviant & $15(60 \%)$ & $7(44 \%)$ & $6(55 \%)$ & $1(9 \%)$ \\
\hline
\end{tabular}

$91 \%$ of the children with poorly controlled asthma had deviant scores on one or both of the Rutter scales and there was a significant association between 'deviance' and quality of control $\left(\chi^{2}=8 \cdot 43 ; \mathrm{df}=3\right.$; $\mathrm{P}<0.05)$.

(b) Malaise Inventory. The poorly controlled children had the largest proportion of mothers $(64 \%)$ with relatively high scores on the Malaise Inventory, but there was no significant difference between the groups.

(c) Junior Personality Questionnaire. There was no evidence of any association between the degree to which the asthma was controlled by medication and either emotionality or extraversion.

Clinical ratings. The relationship between clinical judgements of quality of control and adequacy of drug administration is shown in Table 7. Categories were combined for statistical analysis and the two ratings were shown to be strongly associated $\left(\chi^{2}=11.95, \mathrm{df}=1, \mathrm{P}<0.001\right)$.

Physiological measures. Measurements of peak flow rate agreed with the overall clinical impression of the severity of the asthma (Table 8) and the quality of control (Table 9). Exercise-induced bronchial lability was similar in deviant and nondeviant children (Table 10) but their mean clinic resting peak flow rates were significantly different $(t=2 \cdot 39$; $\mathrm{df}=48 ; \mathrm{P}=0 \cdot 021$ ).

Table 7 Quality of control and adequacy of drug administration

\begin{tabular}{llll}
\hline $\begin{array}{l}\text { Adequacy of } \\
\text { drug } \\
\text { administration }\end{array}$ & \multicolumn{3}{l}{ Quality of control } \\
\cline { 2 - 4 } & $\begin{array}{l}\text { Very good } \\
\text { to good }\end{array}$ & $\begin{array}{l}\text { Average } \\
\text { to poor }\end{array}$ & Total \\
\hline Very good to good & 34 & 8 & 42 \\
Average to poor & 7 & 14 & 21 \\
Total & 41 & 22 & 63 \\
\hline
\end{tabular}

Table 8 Physiology and severity of asthma (drug grouping)

\begin{tabular}{clll}
\hline & Mild & Moderate & Severe \\
\hline $\begin{array}{cll}\text { Mean clinic PEFR } \\
\text { (\% expected) }\end{array}$ & $82 \pm 5$ & $81 \pm 3$ & $69 \pm 4$ \\
Pre-exercise PEFR & $(\mathrm{n}=12)$ & $(\mathrm{n}=20)$ & $(\mathrm{n}=19)$ \\
$\begin{array}{c}\text { (\% expected) } \\
\text { Postexercise }\end{array}$ & $\mathbf{8 5 \pm 4}$ & $\mathbf{8 6} \pm 3$ & $72 \pm 6$ \\
$\%$ fall in PEFR & $56 \pm 6$ & $(\mathrm{n}=17)$ & $(\mathrm{n}=11)$ \\
& $(\mathrm{n}=13)$ & $(\mathrm{n}=17)$ & $(\mathrm{n}=11)$ \\
\hline
\end{tabular}

Tables 8-10, mean \pm SEM given.

Table 9 Physiology and quality of control

\begin{tabular}{|c|c|c|c|}
\hline & Good & Average & Poor \\
\hline $\begin{array}{l}\text { Mean clinic PEFR } \\
\text { (\% expected) } \\
\text { Pre-exercise PELR } \\
\text { ( } \% \text { expected) } \\
\text { Postexercise } \\
\% \text { fall in PEFR }\end{array}$ & $\begin{array}{l}86 \pm 2 \\
(n=19) \\
85 \pm 3 \\
(n=20) \\
28 \pm 5 \\
(n=20)\end{array}$ & $\begin{array}{l}70 \pm 3 \\
(n=21) \\
73 \pm 5 \\
(n=12) \\
34 \pm 6 \\
(n=12)\end{array}$ & $\begin{array}{l}61 \pm 5 \\
(n=10) \\
78 \pm 5 \\
(n=16) \\
35 \pm 6 \\
(n=16)\end{array}$ \\
\hline
\end{tabular}

Table 10 Physiology and psychology comparison

\begin{tabular}{lll}
\hline & $\begin{array}{l}\text { Deviant } \\
\text { children }\end{array}$ & $\begin{array}{l}\text { Nondeviant } \\
\text { children }\end{array}$ \\
\hline $\begin{array}{l}\text { Mean clinic PEFR } \\
(\% \text { expected) }\end{array}$ & $68 \pm 4(n=26)$ & $80 \pm 3(n=25)$ \\
$\begin{array}{c}\text { Pre-exercise PEFR } \\
\text { (\% expected) }\end{array}$ & $77 \pm 4(n=24)$ & $83 \pm 4(n=22)$ \\
$\begin{array}{c}\text { Postexercise \% fall } \\
\text { in PEFR }\end{array}$ & $32 \pm 4(n=24)$ & $32 \pm 4(n=22)$ \\
\hline
\end{tabular}




\section{Discussion}

The results obtained with the parents' and teachers' questionnaires were compared with the results from a population of asthmatic children aged 10 to 12 in the Isle of Wight (Graham et al., 1967), and for the teachers' questionnaire only, with results from a total population of 10-year-old children in an Inner London Borough (Rutter et al., 1974). As Table 11 shows, the percentage of Hammersmith Hospital children with a deviant score on both scales was

Table 11 Rutter scales: comparisons with other studies

\begin{tabular}{|c|c|c|c|}
\hline & $\begin{array}{l}\text { Hammersmith } \\
\text { asthmatics } \\
(n=63) \\
0 \text { deviant }\end{array}$ & $\begin{array}{l}\text { Isle of Wight } \\
\text { asthmatics } \\
(n=c .68) \\
0_{0} \text { deviant }\end{array}$ & $\begin{array}{l}\text { Inner London Borough } \\
\text { population } \\
(n=2043) \\
0 \text { deviant }\end{array}$ \\
\hline $\begin{array}{l}\text { 'A' scale } \\
\text { 'B' scale }\end{array}$ & $\begin{array}{l}44 \\
28\end{array}$ & $\begin{array}{l}10(\mathrm{P}<0.001) \\
11(\mathrm{P}<0.02)\end{array}$ & $\overline{23}(\mathrm{NS})$ \\
\hline
\end{tabular}

significantly higher than that of the Isle of Wight asthmatics but there was no significant difference between the Hammersmith sample and the Inner London Borough population on scores from the teachers' questionnaire. Closer study of the Inner London Borough results (Table 12) show that the

Table 12 Comparison of subgroups in various studies

\begin{tabular}{lllll}
\hline & Emotional & Conduct & Mixed & Total \\
\hline Inner London & & & & \\
Borough & 7 & 10 & 2 & 19 \\
$\quad$ Non-immigrant $\left({ }^{\circ}\right)$ & 7 & 33 & 2 & 42 \\
$\quad$ Immigrant $\left({ }^{\circ}\right)$ & 7 & 14 & 2 & 23 \\
$\quad$ Total $\left(\%^{\prime}\right)$ & $11)$ & 11 & 5 & 27 \\
Hammersmith & & & & \\
$\quad$ Hospital asthmatics $(\%)$ & 11 & & \\
\hline
\end{tabular}

deviant proportion was substantially higher for immigrant children $(41 \%)$ than indigenous children $(19 \%)$ and that the immigrant group tended to have a higher proportion of children with conduct disorders $(33 \%)$ than emotional disorders $(6 \%)$. In the Hammersmith asthmatics, the proportion of children with emotional and conduct disorders was equal $(11 \%)$, despite the fact that $27 \%$ of our children were 'immigrant'. This might suggest a greater trend towards emotional disorder among asthmatics. In fact, of our 15 immigrant asthmatic children, $3(20 \%)$ had emotional disorder, and only one ( $7 \%$ ) had a conduct disorder.

The main objective of this investigation was to study the relationship between psychological measures and clinical measures of severity and the degree of control obtained over the child's asthma by medication rather than to compare the results with those from other studies or with a control group of nonasthmatic children.

Emotional and conduct disorders. No significant relationship was found between the severity of the child's asthma and emotional or conduct disorders as measured by the Rutter scales. Children with deviant scores were as common among those with mild intermittent asthma as they were among children with moderate or severe asthma, but emotional or conduct disorders were significantly more frequent among children whose asthma was poorly controlled by medication. The data show that the relationship between deviance and 'quality of control' held in one direction only (Table 6): that is, children with poorly controlled asthma were very likely to have a deviant score on one or both scales, but a deviant score did not necessarily imply poor control of the child's asthma. Indeed, one-third of the children with well-controlled asthma had deviant scores. However, when the degree of disturbance was taken into account, it was found that the poorly controlled children were more likely to score on both the Rutter scales.

Maternal malaise. The findings in relation to the mother's mental well-being did not show positive evidence that the mother's mental state was related to her child's physical health. We did, however, confirm the findings from the Isle of Wight study (Rutter et al., 1970) that mothers of children identified as deviant by Rutter scales had higher scores on the Malaise Inventory than did mothers of children with a physical handicap only. This result would explain the distribution of malaise scores in this study, with high-scoring mothers being found most frequently among the mothers of children with mild intermittent asthma or with poorly controlled asthma.

Personality. The results of the personality test indicated that these children were no more emotional than children in general but that they tended to be more introverted, particularly the most severe asthmatics. There were, however, no significant differences between the groups of children on either of the personality dimensions.

Implications for clinical management. There was a very close relationship between the clinical ratings of 'quality of control' and 'adequacy of drug administration'. Both these judgements were made by the physician and therefore were not independent of each other, but the implication was that children who received adequate medication were kept well whether or not they had emotional or conduct disorders. This does not necessarily imply that the 
disorder was unrelated to the asthma, but the data shed no light on the nature of the relationship, and for these children 'deviance' did not interfere with satisfactory clinical management. It is also improbable that the child's asthma was currently an important factor in maintaining the disorder.

For those children with poorly controlled asthma, however, the clinical condition was probably a factor in maintaining 'deviance' and the deviant behaviour could have been interfering with clinical management. 8 of the 10 deviant children in this group were believed to be receiving inadequate medication, and there may have been a circular relationship between the child's clinical condition, the emotional or conduct disorder, and inadequate medication, with the poorly controlled asthma helping to maintain the deviance and the deviant behaviour interfering with drug administration. Some form of psychological or psychiatric intervention together with an active attempt to improve drug administration would probably lead to clinical improvement. It might also suggest that very rigorous control of asthma by medication from an early stage in children with deviant scores might prevent this circular relationship from developing.

\section{References}

Alexander, F. (1950). Psychosomatic Medicine. Allen and Unwin, London.
Connolly, N., and Godfrey, S. (1970). Assessment of the child with asthma. Journal of Asthma Research, 8, 31-36.

Eysenck, H. J., and Eysenck, S. B. G. (1975). Manual of the Eysenck Personality Questionnaire. Hodder and Stoughton, London.

Godfrey, S. (1974). Problems peculiar to the diagnosis and management of asthma in children. British Thoracic and Tuberculosis Association Review, 4, 1-16.

Godfrey, S., Kamburoff, P. L., and Nairn, J. R. (1970) Spirometry, lung volumes and airway resistance in normal children aged 5 to 18 years. British Journal of Diseases of the Chest, 64, 15-24.

Graham, P. J., Rutter, M., Yule, W., and Pless, I. B. (1967). Childhood asthma: a psychosomatic disorder? Some epidemiological considerations. British Journal of Preventive and Social Medicine, 21, 78-85.

McNichol, K. N., Williams, H. E., Allan, J., and McAndrew, I. (1973). Spectrum of asthma in children. III. Psychological and social components. British Medical Journal, 4, 16-20.

Pinkerton, P. (1967). Correlating physiologic with psychodynamic data in the study and management of childhood asthma. Journal of Psychosomatic Research, 11, 11-25.

Rees, L. (1956). Physical and emotional factors in bronchial asthma. Journal of Psychosomatic Research, 1, 98-114.

Rutter, M., Tizard, J., and Whitmore, K. (1970). Education, Health and Behaviour. Longman, London.

Rutter, M., Yule, W., Berger, M., Yule, B., Morton, J., and Bagley, C. (1974). Children of West Indian immigrants. I. Rates of behavioural deviance and of psychiatric disorder. Journal of Child Psychology and Psychiatry, 15, $241-262$.

Correspondence to Miss M. Norrish, Department of Psychological Medicine, Hammersmith Hospital, Du Cane Road, London W12 0HS. 